\title{
ANALISA PEREKAMAN DATA SUARA DARI SISTEM BLACKBOX PADA KERETA API
}

\author{
Emy Setyaningsih ${ }^{1}$, M. Andang Novianta ${ }^{2}$, \\ 1) Program Studi Sistem Komputer - Institut Sains \& Teknologi AKPRIND Yogyakarta \\ ${ }^{2)}$ Program Studi Teknik Elektro - Institut Sains \& Teknologi AKPRIND Yogyakarta \\ E-mail: ${ }^{1)}$ emypurnomo@akprind.ac.id , ${ }^{2}$ m_andang@akprind.ac.id
}

\begin{abstract}
Abstrak
Makalah ini akan membahas tentang penerapan black box pada kereta api yang diadopsi pertama kali pada pesawat, dengan parameter perekam suara hingga waktu simpan kurang dari 1 hari 8 jam pada media penyimpanan SD Card. Tujuan dari pengujian pada makalah ini adalah membandingkan sumber suara terhadap jarak penerima, sebagai parameter perubahan tingkat suara " $d B$ ". Sistem perekaman suara yang akan ditempatkan pada kereta api ini menggunakan modul rangkaian terintregasi WTR010. Voice record WTR010 merupakan modul rangkaian terintegrasi untuk merekam suara sendiri atau pun suara dari file music / video pada komputer dengan sangat mudah. Modul ini bisa merekam suara sendiri dan langsung di simpan ke dalam format audio. Format audio yang disediakan oleh modul voice record adalah format AD4 dan wav.

Hasil pengujian modul black box yang diletakkan pada kereta api, dengan mencoba mengucapkan kata "SAYA", suara dapat terekam pada modul perekam suara yang selanjutnya diolah menggunakan "software sound editor" yang disimpan pada SD Card berekstensi "wav". Perbandingan sumber suara terhadap jarak penerima dari pengujian didapatkan sebuah persamaan regresi linier $y=-(31 x-11)$ dan $R^{2}=0.972$. Pengujian ini menghasilkan penekanan suara $d B$ dan frekuensi sample Hz yang berbeda.
\end{abstract}

Kata kunci: black box kereta api, perekaman suara, WTR010

\section{PENDAHULUAN}

Permasalahan perkeretaapian Indonesia saat ini memang diakui sangat rumit, sulit, dinamis dengan tantangan yang terus berkembang. Sejak dulu hingga kini kereta api selalu berhadapan dengan tantangan kompetisi yang tinggi dari moda lain. Jika dulu berhadapan dengan perkembangan otomotif, maka kini tantangan datang dari perangkutan udara dengan tarif yang sangat kompetitif. Namun yang saat ini mengganggu perkeretaapian Indonesia adalah tingginya tingkat kecelakaan. Penyebab tingginya kecelakaan kereta api merupakan akumulasi dari banyak faktor, diantaranya masalah regulasi, manajemen, kondisi prasarana dan sarana, SDM, dan lain-lain.

Saat ini sistem pemantauan lalu lintas kereta api yang dilakukan oleh PT. KAI masih bersifat sederhana dan semi otomatis. Oleh karena itu dibutuhkan alat yang dapat merekam lalu lintas kereta api serta memonitoring letak atau posisi kereta api tertentu secara realtime, sehingga membantu meminimalkan terjadinya kecelakaan kereta api yang disebabkan secara teknis maupun kesalahan manusia. Selain itu juga dibutuhkan alat perekam suara yang dapat memberikan informasi kondisi/keadaan terakhir sebelum terjadinya kecelakaan. Sehingga informasi mengenai penyebab kecelakaan secara pasti 
dapat diketahui dengan adanya alat pemantau posisi kereta api yang dilengkapi alat perekam suara.

Bunyi atau suara adalah pemampatan mekanis atau gelombang longitudinal yang merambat melalui medium. Medium atau zat perantara ini dapat berupa zat cair, padat dan gas. Kebanyakan suara adalah gabungan berbagai sinyal getar terdiri dari gelombang harmonis, tetapi suara murni secara teoritis dapat dijelaskan dengan kecepatan getar osilasi atau frekuensi yang diukur dalam satuan getaran $\mathrm{Hertz}(\mathrm{Hz})$ dan amplitudo atau kenyaringan bunyi dengan pengukuran dalam satuan tekanan suara desibel (dB) (Gold,B.,andN.Morgan, 1999).

WTR010 adalah modul elektronik yang terintregasi untuk penyimpanan suara pada media SD Card. Modul ini bisa merekam suara sendiri dan langsung di simpan kedalam format audio. Format audio yang disediakan oleh modul voice record adalah format AD4 dan wav.

Untuk merekam suara yang terdapat pada kereta api, maka dipasang sebuah black boxtermasuk salah satunya modul voice record. Modul voice record (WTR010) diletakkan pada keretaapi, tepatnya pada ruang masinis untuk mengetahui percakapan diruangan tersebut.

Tujuan pengujian penelitian ini adalah untuk mendapatkan persamaan regresi linier perbandingan nilai tekanan suara $(\mathrm{dB})$, antara penerima (modul WTR010) terhadap jarak sumber (source voice) di dalam kereta api, dengan metode analsis pada "softwaresound editor".

\section{KAJIAN TEORI}

Beberapa penelitian terdahulu yang terkait dengan pengolahan suara atau bunyi diantaranya:

a) Pengenalan pola kata dengan metode anfis (adaptive neuro-fuzzy inference systems), menganalisa dan mengetahui unjuk-kerja ANFIS sebagai perangkat lunak yang menggunakan toolbox Matlab untuk proses pengenalan pola kata melalui spektrum kata, sehingga dapat mengenali ucapan kata dari orang perorang, yang disimulasikan dalam bentuk absensi (Maulidya S.I, 2007).

b) Text to voice with angry condition, penelitian ini membahas text to voice pada komputer, dengan penambahan emosi marah pada keluaran suara bahasa lisan dalam setiap suku kata, namun kurangnya penelitian pada bahasa untuk transkripsi teks dalam bahasa Indonesia dengan mempertimbangkan fonologi bahasa Indonesia, memotivasi untuk membuat teks bahasa Indonesia untuk konteks yang sering digunakan, oleh karena untuk melakukan penelitian bahasa Indonesia, teks yang sering digunakan dalam transkrip percakapan sehari-hari seperti e-mail atau chatting melalui internet atau layanan pesan teks telepon, dan khususnya pada robot bicara (Alamsyah R, 2011).

c) (Utomo B.A., dkk, 2011) meneliti tentang analisis karakteristik suara manusia berdasarkan frekuensi fundamental dan tingkat usia pada pelajar SLTP dan SLTA, penelitian ini membahas tentang pengambilan data rekaman suara digital dengan mengambil obyek pelajar SLTP dan SLTA berusia 13 hingga 18 tahun. Tiap tingkat usia diambil sebanyak 8 responden laki-laki dan 8 responden perempuan, tiap responden memberikan sebanyak 10 sampel dengan kata terucap "kamu". Frekuensi fundamental didapatkan dengan menggunakan metode cepstrum dan autokorelasi yang telah terintegrasi di dalam software COLEA. Tiap tingkat usia dilakukan pendugaan interval rata-rata f0 sebagai parameter populasinya serta dilakukan uji hipotesis beda dua rata-rata untuk diketahui kesamaan antar parameter rata-rata f0 tiap tingkat usia. Hubungan antara f0 dan usia didapatkan menggunakan analisis regresi. 


\subsection{Kajian Voice Record WTR010}

Voice record merupakan modul rangkaian terintegrasi untuk merekam suara sendiri atau pun suara dari file musik / video pada komputer dengan sangat mudah sekali. Modul perekaman suara WTR010 yang nampak pada Gambar 1 adalah modul yang bisa merekam suara sendiri dan langsung di simpan kedalam format audio. Format audio yang disediakan oleh modul voice record adalah format mp3 dan wav.

a) File format4 bit MA-APCM WAV dengan akiran "WAV" serta file AD4, dengan akhiran "AD4".

b) Nama file harus 4 digit dan nama file suara dimulai dari 0000 .

c) Penyimpanan file disimpan pada root direktori kurang dari 511 file.

d) Antarmuka I2C menggunakan level tegangan 3.3 - 5 Volt.

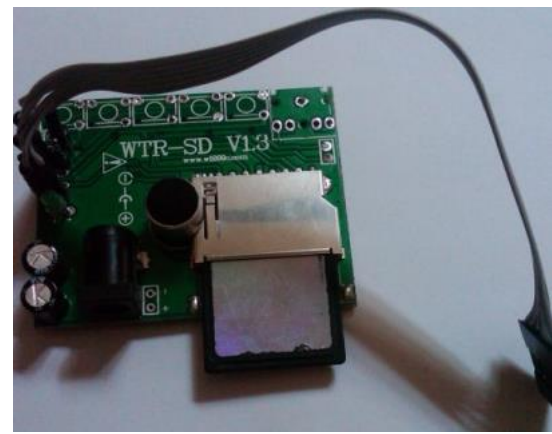

Gambar 1. Modul perekaman suara WTR010

\section{METODE PENELITIAN}

Pada Gambar 2, diperlihatkan bentuk perekam data secara utuh dengan tempat pelindung dan sistem elektronik di dalamnya. Sistem elektronik terjaga di dalam akrilik yang tidak mempengaruhi kinerja penerima sinyal GPS dan modem GSM. Desain box akrilik juga didesain agar mudah dalam pengoperasian dan penggantian simcard GSM. Baterai Li-ion $800 \mathrm{maH}$ sebagai backup tegangan yang kedua ketika ACCU (tegangan utama) tidak dipasang. Pengisian ulang baterai secara otomatis (autocharging). Backup baterai ini juga sebagai alarm warning (peringatan) ketika ACCU (tegangan utama) dilepas.

Desain rangkaian PCB layout dan tempat kotak (box) yang dibuat agar mudah dalam perbaikan maupun pengoperasian. Peletakan dengan menggunakan konsep bentuk tumpukan (stacking) pada modul rangkaiansehinggalebih sederhana dan mudah untuk perakitan sistem perekam suara, unit kendali, modul GSM dan modul GPS. Dengan metode stacking akan membuat dimensi bisa lebih ramping.

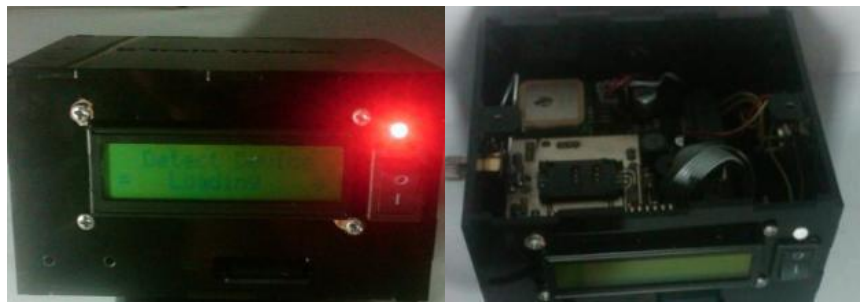

Gambar 2. Tata letak rangkaian elektronik dan box

Pengujian perekaman suara dilakukan dengan mengumpulkan 3 contoh suara yang disimpan pada modul perekam suara WTR010 dengan kapasitas SD Card 512Mb, tepatnya di ruang masinis dengan durasi 24 jam. Pengujian ini dilakukan ketika kereta 
api sedang dalam perjalanan dengan mengujikan ucapakan kata yang sama, tetapi dengan jarak yang berbeda. Hasil pengujian yang dilakukan didapatkan tekanan suara yang semakin kecil, hal ini membuktikan bahwa nilai jarak (meter) pada sumber suara berbanding terbalik dengan nilai tekanan suara.

\section{HASIL DAN PEMBAHASAN}

Hasil penyimpanan rekaman suara pada media SD Card dapat dibuka menggunakan software sound editor, didalam software ini sudah terdapat analisis frekuensi dan kualitas tekanan suara (dB). Jika durasi simpan SD Card yang berukuran 32 Mbyte adalah 2 jam, maka estimasi durasi simpan SD Card yang berukuran $512 \mathrm{Mb}$ dapat menyimpan hingga 1 hari 8 jam.

\begin{tabular}{ll}
\hline Size & Jam \\
\hline $32 \mathrm{Mb}$ & 2 jam \\
$512 \mathrm{Mb}$ & $\mathrm{T}$ \\
\hline
\end{tabular}

$$
\mathrm{T}=\frac{512 \times 2}{32}=32 \mathrm{jam}=1 \text { hari } 8 \text { jam. }
$$

Hubungan antara variabel pada suatu data yang terdiri atas dua atau lebih variabel dapat dipelajari dengan analisis regresi. Hubungan yang didapat dinyatakan dalam bentuk matematik yang menyatakan hubungan fungsional antara variabel-variabelnya. Ada dua jenis variabel dalam analisis regresi, yaitu variabel bebas atau variabel prediktor dan variabel tak bebas atau variabel respon. Regresi dengan $\mathrm{X}$ merupakan variabel bebasnya dan $\mathrm{Y}$ sebagai variabel tak bebasnya dinamakan regresi $\mathrm{Y}$ atas $\mathrm{X}$, ditulis sebagai $\mathrm{Y}=\mathrm{a}+\mathrm{bX}$. Persamaan regresi atas hasil pengamatan yang didapat dapat dilakukan dengan metode tangan bebas dan metode kuadrat terkecil. Metode tangan bebas merupakan metode kira-kira menggunakan diagram pencar berdasarkan hasil pengamatan, sumbu tegak untuk variabel tak bebas sedangkan sumbu datar adalah variabel bebas. Bentuk regresi dapat ditentukan dengan memperhatikan letak titik-titik dalam diagram. Jika letak titik-titik tersebut berada di sekitar garis lurus maka cukup beralasan untuk menduga sebagai regresi linier. Jika letak titik-titik disekitar garis lengkung maka dikatakan sebagai regresi onlinier. Metode kuadrat terkecil berpangkal pada kenyataan bahwa jumlah pangkat dua (kuadrat) dari jarak antara titik-titik dengan garis regresi yang dicari harus sekecil mungkin. Dalam pengujian penelitian ini digunakan analisis regresi menggunakan metode kuadrat terkecil.

Perekaman suara ini bertujuan untuk mengetahui proses percakapan di dalam kereta yang disimpan pada SD Card $512 \mathrm{Mb}$, tepatnya di ruang masinis dengan durasi 24 jam. Tabel 1 adalah hasil dari pengujian penyimpan tingkat tekanan suara terhadap jarak sumber suara di dalam kereta. Dengan menggunakan frequency analysis yang terdapat softwaresound editor didapat nilai $\mathrm{dB}$ (tingkat tekenan suara) yang disimpan pada media SD Card.

Tabel 1. Kualitas hasil perekaman suara

\begin{tabular}{rrrr}
\hline oN & $\begin{array}{r}\text { srnmws ka ra J } \\
\text { suara (meter) }\end{array}$ & $\begin{array}{r}\text { Penekanan } \\
\text { Suara(dB) }\end{array}$ & $\begin{array}{c}\text { Sampling } \\
\text { Frekuensi }\end{array}$ \\
\hline 1 & 0.5 & -6 & 3619 \\
s2 & s 1 & -17 & 512 \\
3 & 1.5 & -37 & 136 \\
\hline
\end{tabular}


Hasil pengujian pada tabel 1 didapatkan persamaan regresi linier sebagai berikut: $\mathbf{y}$ $=-(31 x-11)$ dan $R^{2}=\mathbf{0 . 9 7 2}$ dan Gambar 3 menunjukkan grafik pendekatan linier antara sumber suara dan penerima.

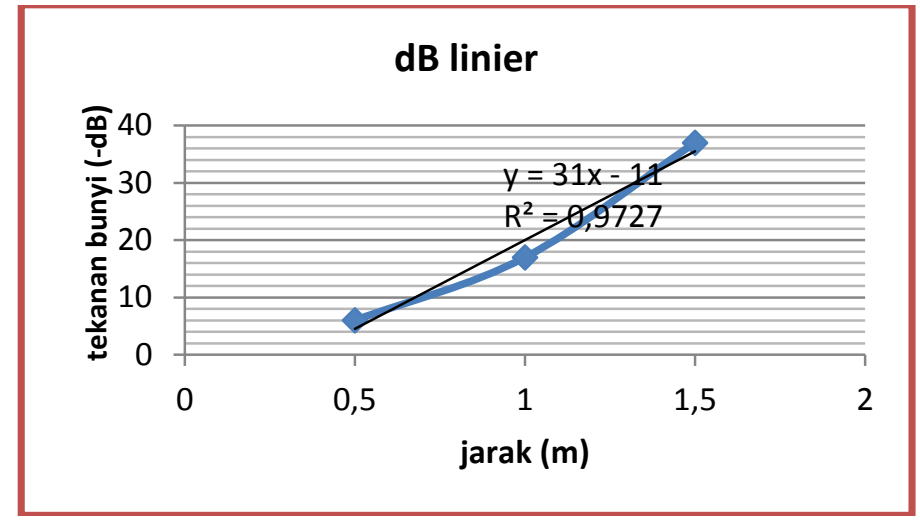

Gambar 3. Pendekatan linier antara sumber suara dan penerima (WTR010)

Pengujian terhadap modul perekam dengan cara mengucapkan kata "SAYA" dengan jarak yang berbeda dari alat pemantau. Hasil pengujian didapatkan hasil penekan suara $(\mathrm{dB})$ dan frekuesi sampel $(\mathrm{Hz})$ yang berbeda. Perekaman suara yang disimpan pada SD Card nantinya akan ber-ekstensi (*.Wav).

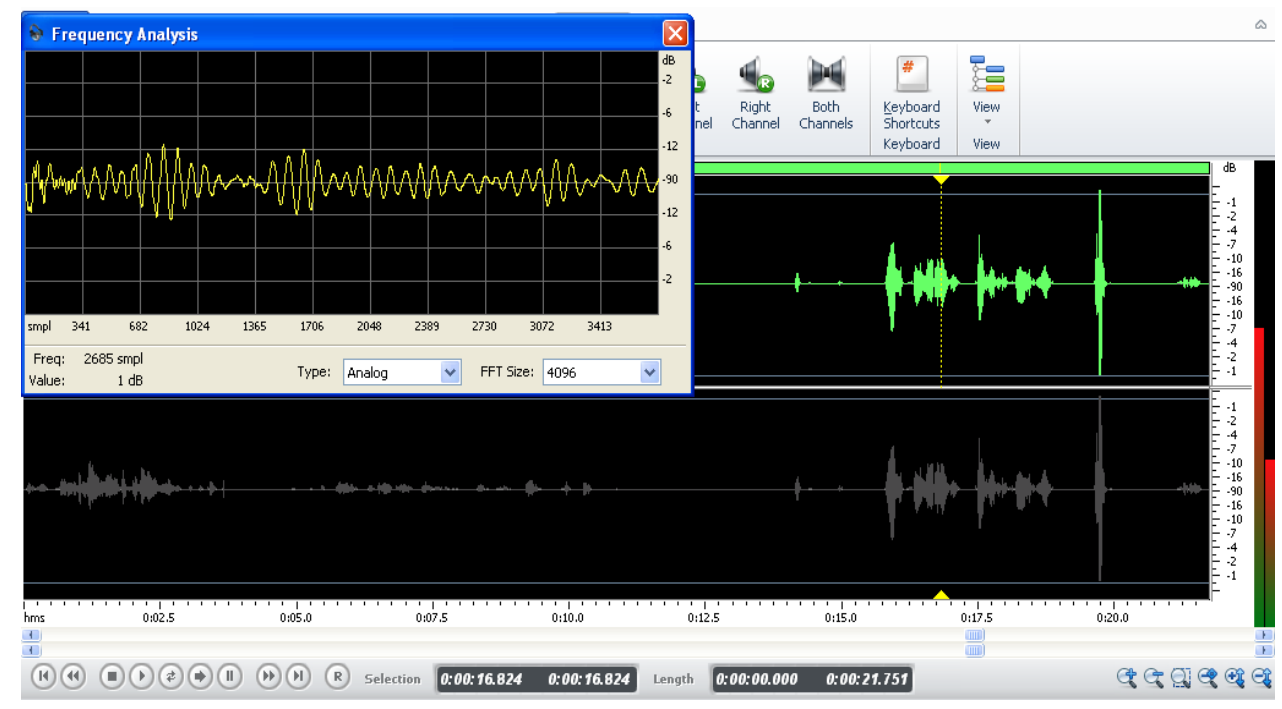

\section{Gambar 4. Perekaman suara pada kereta Api}

Hasil dari perekaman suara ini dapat diputar dan dianalisa menggunakan software power sound editor, yaitu software yang tersedia secara gratis yang menyediakan fasilitas pola pengukuran frekuensi dan tekanan bunyi, serta pengurangan bissing (noise), seperti pada Gambar 4. 


\section{SIMPULAN}

Dari hasil penelitian dan pembahasan dapat disimpulkan bahwa:

a) Suara pada WTR010 yang tersimpan pada SD Card memiliki file format "*.wav" atau "AD4".

b) Perekaman suara dapat tersimpan selama 1 hari 8 jam.

c) Analisis regresi untuk perubahan nilai tekanan suara $(\mathrm{dB})$ terhadap jarak sumber suara (source voice), memiliki persamaan: $\mathbf{y}=\mathbf{-}(\mathbf{3 1 x}-\mathbf{1 1})$ dan $\mathbf{R}^{\mathbf{2}}=\mathbf{0 . 9 7 2}$.

d) Grafik regresi menunjukkan adanya penurunan besarnya $\mathrm{dB}$ seiring bertambahnya jarak sumber suara yang diterima.

\section{UCAPAN TERIMA KASIH}

Ucapan terima kasih kami sampaikan kepada Kopertis wilayah V DIY Kementrian Pendidikan dan Kebudayaan yang telah mendanai kegiatan penelitian ini sesuai dengan Surat Perjanjian Pelaksana Hibah Penelitian Nomor: 1331/K5/KM/2014, Tanggal 6 Mei 2014, melalui dana Penelitian Hibah Bersaing.

\section{DAFTAR PUSTAKA}

[1] Aryo Baskoro Utomo,Wahyudi, Achmad Hidayatno, 2011, Analisis Karakteristik Suara Manusia Berdasarkan Frekuensi Fundamental Dan Tingkat Usia Pada Pelajar SLTP dan SMA,Fakultas Teknik UNDIP, Semarang.

[2] Gold,B.,andN.Morgan, 1999, SpeechandAudio SignalProcessing:ProcessingandPerception of Speechand Music,John Wiley \& Sons, Inc., New York.

[3] Robi Alamsyah, 2011, Text To Voice With Angry Condition, Fakultas Teknik Universitas Indonesia, Depok.

[4] Siti Imsyawati Maulidya, S.T., M.Kom, 2007, Pengenalan Pola Kata Dengan Metode Anfis (Adaptive Neuro-Fuzzy Inference Systems), Jurusan Teknik Informatika, IST AKPRIND, Yogyakarta. 